\title{
Forced convection and heat transfer around a bounded cylinder
}

\author{
Blanka Skočilasová ${ }^{1, *}$, Jan Skočilas $^{2}$, Josef Soukup ${ }^{1}$ \\ ${ }^{1}$ J. E. Purkyne University in Usti nad Labem, Faculty of Production Technology and Management, \\ Pasteurova 3334/7, 40096 Usti nad Labem, Czech Republic \\ ${ }^{2}$ Czech Technical University in Prague, Faculty of Mechanical Engineering, Department of Process \\ Engineering, Technická 4, 16607 Praha 6, Czech Republic
}

\begin{abstract}
The article deals with the heat transfer solution in the fluid flow inside a pipe, the small tube is inserted into the pipe and its axis is perpendicular to the axis of the pipe. The fluid is water, the regime of the fluid flow is turbulent. The small tube is loaded by the internal source of the heat, the power of the source is constant and homogenous over the small tube surface and the cold water cools down the small tube. The analysis of the described problem helps to design the experimental model (the heat source above all) to validate the CFD results. The work included the numeric and analytic method. The model was prepared with the aim to investigate large amount of the variants of the geometric set up (the tube and pipe diameters ratio, the geometrical aspect ratio, corresponding stabilization length of the pipe for given diameter), the flow properties (variation of the velocity values, Reynolds number) and the power of the heat source (ensuring the measurable differences of the temperatures on the tube surface, large Nusselt number). The effect of the constrained space has been observed and described, compare to the free fluid flow.
\end{abstract}

Keywords: convective heat transfer, Nusselt number, flow over cylinder

\section{Introduction}

The most important process parameter of the heat exchanger design [1] is heat transfer surface directly linked with total heat transfer coefficient and convective heat transfer coefficient respectively. The article deals with investigation of momentum and heat transfer within specific simple.

The described problem is well known and investigated for many decades [2]. The several phenomena can be observed during inertia and heat transfer in the fluid near or behind immersed body which is overflowed by fluid. Many articles exist related to experimental [3-5] or numerical investigation [6-8] of the horizontal tube inserted into the free stream of fluid for low or high Reynolds number. In the last decade the main effort was done in investigation of the heat transfer around the heated cylinder during mixed convection, i.e. forced convection with buoyancy effect. The authors of articles related to heat transfer at surface of overflowed tube applied CFD simulation very often to investigate

\footnotetext{
* Corresponding author: blanka.skocilasova@ujep.cz

Reviewers: Wiestawa Piekarska, Milan Žmindák
} 
the problem with (assumed) unconstrained surrounding, e.g. natural convection in the fluid with immersed horizontal pipe [6-8]. Many authors preferred CFD solution of the problem by own code using standard method, e.g. SIMPLE algorithm [6] or Galerkin weighted residual finite element method [7], DNS approach [8-9] or they were using the commercial software ANSYS [10-12]. The research devoted to stream turbulence intensity and local perturbation generated behind the cylinder or generation of unsteady wake are also frequented, both experiment [4, 13-14] and numerical simulation [6-7] were performed by authors.

The similar problem with heated tube in the channel investigated Bayruk [15]. The difference of the presented article is to investigate the constrained environment effect on the heat transfer coefficient. After the suitable model will be developed, the temperature probe and the experimental stand will be build up according to [16-17]. The heated cylinder is equipped by surface thermocouples to measure the wall temperature on the cylinder perimeter, which allows to determine the local values of convective heat transfer coefficient.

\section{Materials and methods}

The small tube is inserted into the large pipe. The tube is positioned perpendicularly to pipe axis. Inner diameters of the pipe are $D=60 \mathrm{~mm}$ and $300 \mathrm{~mm}$, outer diameter of the tube is $d=12 \mathrm{~mm}$, the length of the pipe is $L=4 \mathrm{~m}$, the stabilization length is $3 \mathrm{~m}$, the exhaust part (behind the tube) has length $1 \mathrm{~m}$. In the text of the article term "tube" represents small object inserted into the stream and term "pipe" is used for description of the channel. The physical parameters of water were used for simulation of fluid flow.

The diameters of the pipe or the ratios of the cross-section of the pipe to perpendicular surface projection of the small tube were mutually different more than five times. These geometries ensure incorporate the effect of the close environment, i.e. the effect of the pipe walls, into the final equations describing the heat transfer process under various conditions.

\subsection{Numerical simulation}

The models were created in the software ANSYS - Fluent 14.0. A various geometrical characteristics, flow properties and powers of heat source were applied. One diameter of the inserted tube $12 \mathrm{~mm}$ and two diameters of the pipe 60 and $300 \mathrm{~mm}$ were modeled. The model with $60 \mathrm{~mm}$ pipe diameter had 828 thousands of elements and with $300 \mathrm{~mm}$ had 1318 thousands of elements. The $k$ - $\omega$ model with wall function SST was chosen [18]. The heat flux related to surface was set up as boundary condition to wall of the tube (small cylinder).

The simulation was performed with flow velocities $0.16,0.53,2.66,5.32,15.95$ and $26.58 \mathrm{~m} . \mathrm{s}^{-1}$, in both diameters of pipe. Also 3 values of the power of the heat source were applied $26826 \mathrm{~W} . \mathrm{m}^{-2}, 44711 \mathrm{~W} . \mathrm{m}^{-2}$ and $89422 \mathrm{~W} . \mathrm{m}^{-2}$ which corresponds to the values of total power 60 and $100 \mathrm{~W}$ for small diameter of the pipe and 100, 500 and $1000 \mathrm{~W}$ for large diameter of the pipe. The smallest value of the power of the heat source was not used in case of pipe with $60 \mathrm{~mm}$ diameter, because the effect of the heat source was negligible on the temperature of the fluid and observed differences between the wall temperature and the fluid temperature were too small. 


\subsection{Correlations}

In this part the applied relations for the heat transfer coefficient determination are described. The equations were found by the literature search [1, 18-24] and they evaluate mean value of the convective heat transfer coefficient for the transversal flow over the cylinder in the unconstrained environment. The valid range of these equations was respected.

The following equations are possible to use for the fluid overflow around the pipe (1), (2) and (3) [22], where the determining dimension is outer diameter of the tube and the determining velocity is bulk velocity of the fluid stream, the ranges of validity are as follow: equation (1a) $5<\operatorname{Re}<10^{3}$, equation (1b) $10^{3}<\operatorname{Re}<2 \cdot 10^{5}$ and equation (1c) $2 \cdot 10^{5}<\operatorname{Re}<2 \cdot 10^{6}$

$$
\begin{gathered}
N u=0.5 \operatorname{Re}^{0.5} \operatorname{Pr}^{0.38}\left(\operatorname{Pr} / \operatorname{Pr}_{s}\right)^{0.25}, \\
N u=0.25 \operatorname{Re}^{0.6} \operatorname{Pr}^{0.38}\left(\operatorname{Pr} / \operatorname{Pr}_{s}\right)^{0.25}, \\
N u=0.023 \operatorname{Re}^{0.8} \operatorname{Pr}^{0.37}\left(\operatorname{Pr} / \operatorname{Pr}_{s}\right)^{0.25},
\end{gathered}
$$

Whitaker relation is also possible to use [23]

$$
N u=\left(0.4 \operatorname{Re}^{1 / 2}+0.06 \operatorname{Re}^{2 / 3}\right) \operatorname{Pr}^{0.4}\left(\frac{\mu}{\mu_{w}}\right)^{1 / 4},
$$

within the range $0.67<\operatorname{Pr}<380$ and $3.5<\operatorname{Re}<7.610^{4}$.

For the perpendicular overflow around the infinite cylinder [1] see (3a) for $0<\operatorname{Re}<$ $4 \cdot 10^{3},(3 b)$ for $4 \cdot 10^{3}<\operatorname{Re}<4 \cdot 10^{4}$ and $(3 \mathrm{c})$ for $4 \cdot 10^{4}<\operatorname{Re}<4 \cdot 10^{5}$

$$
\begin{gathered}
N u=0.683 \operatorname{Re}^{0.466} \operatorname{Pr}^{1 / 3}, \\
N u=0.193 \operatorname{Re}^{0.618} \operatorname{Pr}^{1 / 3}, \\
N u=0.027 \operatorname{Re}^{0.805} \operatorname{Pr}^{1 / 3},
\end{gathered}
$$

In the literature [19] Churchill-Bernstein equation can be found

$$
N u=0.3+\frac{0.62 \operatorname{Re}^{0.5} \operatorname{Pr}^{1 / 3}}{\left[1+\left(\frac{0.4}{\operatorname{Pr}}\right)^{2.3}\right]^{0.25}}\left[1+\left(\frac{\mathrm{Re}}{28200}\right)^{5 / 8}\right]^{0.8}
$$

for $\operatorname{Re} \cdot \operatorname{Pr}>0.2$, and for Reynolds number in range $7 \cdot 10^{4}<\operatorname{Re}<4 \cdot 10^{5}$ it is recommended to increase the calculated value by $20 \%$. For the estimated calculation McAdams equation can be used [19]

$$
N u=k \cdot \operatorname{Re}^{m} \operatorname{Pr}^{n}
$$

where the values of the coefficient $k$ and exponents $m$ and $n$ depend on the Re, see [19]. 


\section{Results and discussion}

The results are divided into two sections which contain the simulation and the correlations results.

\subsection{Numerical simulation}

In the figure 1 there is presented the results for same geometry of the model, $D=60 \mathrm{~mm}, d$ $=12 \mathrm{~mm}$. The figures differ in the presentation of the contour temperature on the tube wall for the different velocities and power of the heat source. Only contour of small inserted object - tube is presented in the pictures.

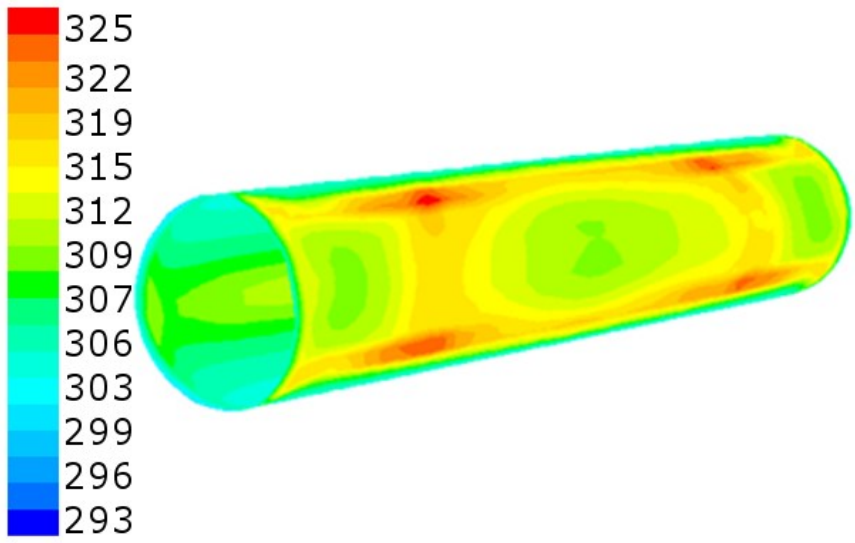

Fig. 1. Contours of static temperature on the tube wall - rear side, $D=60 \mathrm{~mm}, d=12 \mathrm{~mm}$, $w=0.16 \mathrm{~m} . \mathrm{s}^{-1}, P=60 \mathrm{~W}, T_{\min }=293 \mathrm{~K}, T_{\max }=325 \mathrm{~K}, T_{\text {mean }}=309 \mathrm{~K}$

Table 1. Mean value of the convective heat transfer coefficient on the tube surface, $D=60 \mathrm{~mm}, d=$ $12 \mathrm{~mm}$, power of source $P_{\mathrm{m}}=44711 \mathrm{~W} \cdot \mathrm{m}^{-2}$

\begin{tabular}{|c|c|c|c|}
\hline velocity & $\boldsymbol{t}_{\boldsymbol{s}}$ & $\boldsymbol{t}_{\boldsymbol{s}} \boldsymbol{-} \boldsymbol{t}_{\boldsymbol{t}}$ & $\bar{\alpha}$ \\
\hline $\mathbf{m . s}^{-\mathbf{2}}$ & ${ }^{\circ} \mathbf{C}$ & ${ }^{\circ} \mathbf{C}$ & $\mathbf{W} \cdot \mathbf{m}^{-\mathbf{2}} \cdot \mathbf{K}^{-\mathbf{1}}$ \\
\hline 0.16 & 46.28 & 26.28 & 1701.12 \\
\hline 0.53 & 33.09 & 13.09 & 3414.42 \\
\hline 2.66 & 23.57 & 3.57 & 12528.59 \\
\hline 5.32 & 21.96 & 1.96 & 22861.89 \\
\hline 15.95 & 20.67 & 0.67 & 66595.67 \\
\hline 26.58 & 20.38 & 0.38 & 118603.11 \\
\hline
\end{tabular}

$t_{\mathrm{s}}$ - wall temperature, $t_{t}$ - mean value of the temperature of the fluid.

The mean values of heat transfer coefficient are presented in the table 1 , the profile of the local values of the heat transfer coefficient is presented in the figure 2 . The symmetric profile of the coefficient presented in the figure 2 was expected, according to data from literature. The perpendicular position in the tube surface is represented by angle in the horizontal axis. The peaks of local values represent the location of the boundary layer separation from the surface. The maximum values of the coefficient appear at the both border of the tube, where the effect of the pipe wall can be observed. The rest of the variations of investigated cases were performed by the same described way. 


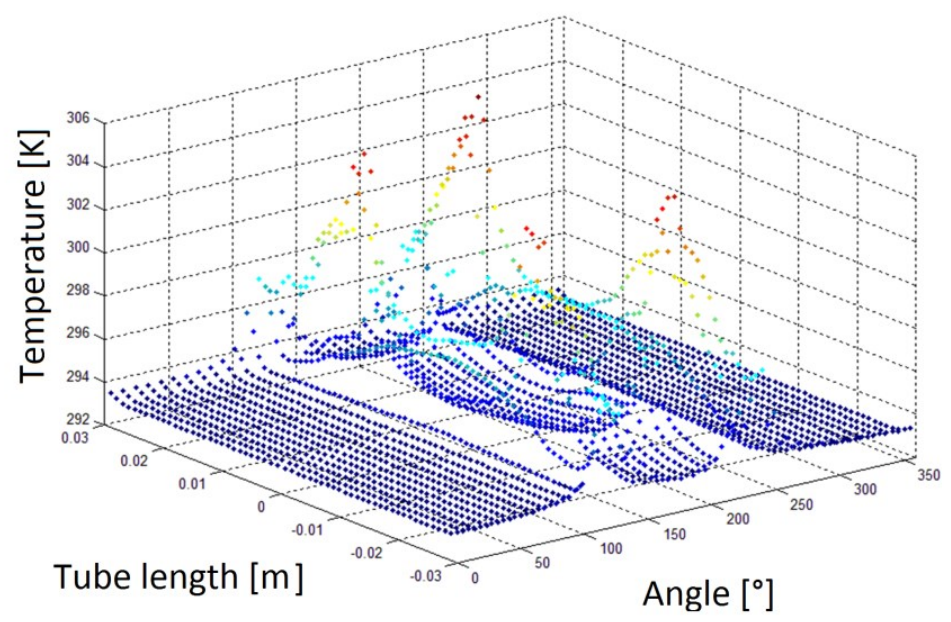

Fig. 2. Local values of the convective heat transfer coefficient for $D=60 \mathrm{~mm}, d=12 \mathrm{~mm}$, $w=0.16 \mathrm{~m} . \mathrm{s}^{-1}, P=60 \mathrm{~W}\left(P_{\mathrm{m}}=26826 \mathrm{~W} \cdot \mathrm{m}^{-2}\right)$

\subsection{Applied correlation}

The equations (1a) to (4b) were used to evaluate the heat transfer coefficient, and the computation results are summarized in the table 2 and for each velocity the corresponded equation (validity of Re range) is used.

Table 2. Mean values of heat transfer coefficient, correlations, $D=60 \mathrm{~mm}, d=12 \mathrm{~mm}$, $P_{m}=44711 \mathrm{~W} \cdot \mathrm{m}^{-2}$, according to equations (1a) to (4b)

\begin{tabular}{|c|c|c|c|c|c|}
\hline $\boldsymbol{w}$ & $\mathbf{R e}_{\mathbf{d}}$ & \multicolumn{5}{|c|}{$\boldsymbol{\alpha}$} \\
\hline $\mathrm{m}^{-\mathrm{s}^{-1}}$ & & \multicolumn{4}{|c|}{$\mathrm{W} . \mathrm{m}^{-2} \mathrm{~K}^{-1}$} \\
\hline & & $\mathbf{1 a})$ & $\mathbf{2})$ & $\mathbf{3 a})$ & $\mathbf{4 b})$ \\
\hline $\mathbf{0 . 1 6}$ & 1916.2 & 2468.87 & 2135.77 & 2200.53 & 2110.27 \\
\hline & & $\mathbf{1 b})$ & $\mathbf{2})$ & $\mathbf{3 b})$ & $\mathbf{4 b})$ \\
\hline $\mathbf{0 . 5 3}$ & 6347.3 & 5446.89 & 3988.32 & 4111.96 & 3826.03 \\
\hline & & $\mathbf{1 b})$ & $\mathbf{2})$ & $\mathbf{3 b})$ & $\mathbf{4 b})$ \\
\hline $\mathbf{2 . 6 6}$ & 31856.2 & 13360.80 & 10396.33 & 11143.54 & 10071.92 \\
\hline & & $\mathbf{1 b})$ & $\mathbf{2})$ & $\mathbf{3 c})$ & $\mathbf{4 b})$ \\
\hline $\mathbf{5 . 3 2}$ & 63712.3 & 20024.04 & 21585.18 & 18934.6 & 18171.07 \\
\hline & & $\mathbf{1 b})$ & $\mathbf{3 c})$ & $\mathbf{4 a})$ & $\mathbf{4 b})$ \\
\hline $\mathbf{1 5 . 9 5}$ & 191017.2 & 38416.15 & 45826.8 & 39597.03 & 43738.08 \\
\hline & & $\mathbf{1 b})$ & $\mathbf{2})$ & $\mathbf{3 c})$ & $\mathbf{4 b})$ \\
\hline $\mathbf{2 6 . 5 8}$ & 318322.1 & 62489.41 & 69129.58 & 57761.2 & 65810.49 \\
\hline
\end{tabular}

The correlations and numerical solutions were compared. The comparison served to determine the region in which it is possible to generalize the used physical conditions and derived new equation describing investigated problem. 


\subsection{Suggested correlation for Nusselt number}

Let assume the general equation for Nusselt number in the following common form

$$
N u=\Phi \cdot \operatorname{Re}^{0.8} \operatorname{Pr}^{1 / 3}\left(\frac{d}{D}\right)^{\Psi}
$$

where constants $\Phi$ and $\Psi$ have to be evaluated. The part $d / D$ of equation represents the dependence both investigated geometries, ration between diameters of inserted tube and pipe. Due to the fact that there are four mutually dependent parameters, it is necessary to simplify the identification process of the parameters by the definition of several assumptions. These assumptions will make the identification process of the parameter realizable and more reliable.

For the total range of Reynolds numbers from 3000 to 320000 we assume the value of the exponent of Reynolds number is 0.8 and is independent on the constants $\Phi$ and $\Psi$.

By the same method we analyzed the Prandtl number exponent. The value of this exponent oscillates around $1 / 3$. We assume this value in the proposed equation (5).

To determine the values of constant $\Phi$ and $\Psi$ we used the standard solver included in the common software e.g. Matlab or Excel. At the beginning we estimated initial values of the coefficients and by nonlinear regression we found out the accurate values correspond to best fit of the equation (6) and results of the simulation. The minimization of least squares was applied.

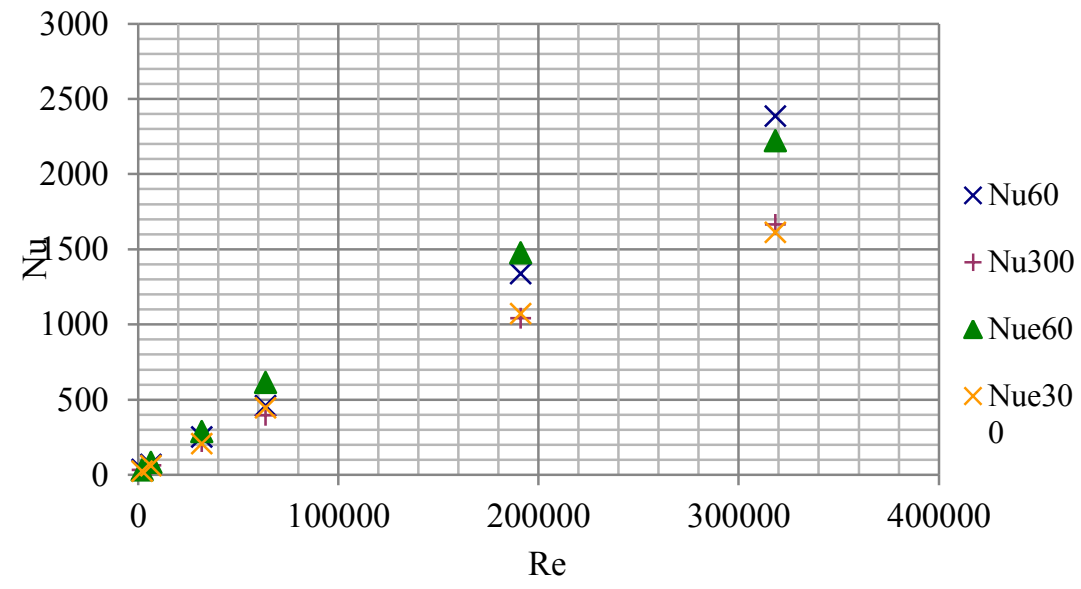

Fig. 3. Dependence of Nusselt number on the Reynolds number for $D=60$ and $D=300 \mathrm{~mm}$, comparison of the simulation values and result of the proposed new equation (6); Nu60, Nu300 are Nusselt numbers obtained from simulation, Nue60, Nue300 are Nusselt numbers evaluated from equation (6)

In the figure 3 the relationship between Reynolds and Nusselt number is presented. The comparison of the simulation and equation (6) with new obtained constants is shown in the figure 3 .

The best fit of the trends obtained by simulation and regression analysis for constant Prandtl number and range of Reynolds number from 3000 to 350000 was obtained for values of constants $\Phi=0.25$ and $\Psi=0.2$.

Final equation with optimized parameters is

$$
N u=0.25 \cdot \operatorname{Re}^{0.8} \cdot \operatorname{Pr}^{1 / 3} \cdot\left(\frac{d}{D}\right)^{0.2}
$$


and it is valid for $d=0.012 \mathrm{~m}, 0.06 \mathrm{~m}<D<0.3 \mathrm{~m}, 3000<\operatorname{Re}<3.5 \cdot 10^{5}, \operatorname{Pr}=7$, which also express it limitation.

The difference of the new equation is caused by the fact, that all equation mentioned in the literature are intended for overflow in unconstrained space e.g. infinite tube length. The new equation involves the effect of the connection wall of the tube and wall of the pipe on the velocity field in this place and consequently influences the heat transfer in this area.

\section{Conclusions}

The comparison of the correlations and simulation results for evaluation of the mean valued of the convective heat transfer coefficient on the tube wall with inner source of heat placed perpendicularly to the fluid stream in the pipe was performed.

From comparison it was found that the highest differences were obtained for highest values of Reynolds number. It is obviously caused by effect of the constrained space around the tube, where the modification of the velocity field by these constrains is the most significant. It can be seen from investigation that the maximum of local values of convective heat transfer coefficient appears at these locations, i.e. near the connection of the walls, where the intensity of turbulence is highest and the biggest vortices are created. Theoretically the wall connection should slow down the fluid flow due to friction of the fluid at walls, but with respect to investigated geometry the geometric layout creates small jets at the vicinity of the wall connection, which increase the heat transfer, compared to the values at the rest of geometry.

The equation for calculation Nusselt number concerning the effect of the geometrical constrains of the investigated models was proposed with respect to similar form of the equations from literature. Constants of the equation were found by regression analysis of the results obtained by simulation.

This work was supported by SGA (Students Grant Agency) UJEP-SGS-173-05-01 Jan Evangelista Purkyně University in Ústí nad Labem, Czech Republic.

\section{References}

1. J. H. Lienhard, A Heat Transfer Textbook. third edition, Phlogiston Press. Cambridge, Massachusetts, USA, (2008).

2. A. Žukauskas, Enhancement of forced convection heat transfer in viscous fluid flows. Int. J. Heat Mass Transfer 37, 207-212 (1994)

3. F. Dumouchel, J. C. Lecordier, P. Paranthoen, The effective Reynolds number of a heated cylinder. Int. J. Heat Mass Transfer 41, 1787-1794 (1998)

4. C. K. Huang, Y. J. Cheng, Y. P. Kang, Combined effect of grid turbulence and unsteady wake on convective heat transfer around a heated cylinder. Int. Comm. Heat Mass Transfer 34, 1091-1100 (2007)

5. R. Perrin, M. Braza, E. Cid, S. Cazin, P. Chassaing, C. Mockett, T. Reimann, F. Thiele, Coherent and turbulent process analysis in the flow past a circular cylinder at high Reynolds number. J. Fluid and Structures 24, 1313-1325 (2008)

6. S. Bhattacharyya, A. K. Singh, Vortex shedding and heat transfer dependence on effective Reynolds number for mixed convection around a cylinder in cross flow. Int. J. Heat Mass Transfer 53, 3202-3212 (2010)

7. M. M. Billah, M.M. Rahman, U. M. Sharif., N.A. Rahim, R. Saidur, M. Hasanuzzaman, Numerical analysis of fluid flow due to mixed convection in a lid- 
driven cavity having a heated circular hollow cylinder. Int. Com. Heat Mass Trans. 38, 1093-1103 (2011)

8. M. Boirlaud, D. Couton, F. Plourde, Direct Numerical Simulation of the turbulent wake behind a heated cylinder. Int. J. Heat Fluid Flow 38, 82-93 (2012)

9. J. G. Wissink, W. Rodi, Heat transfer from the stagnation area of a heated cylinder at $R e_{D}=140,000$ affected by free-stream turbulence. Int. J. Heat Mass Transfer 54, 2535-2541 (2011)

10. G. Juncu, A numerical study of momentum and forced convection heat transfer around two tandem circular cylinders at low Reynolds numbers. Part II: Forced convection heat transfer. Int. J. Heat Mass Transfer 50, 3799-3808 (2007)

11. N. Mahir, Z. Altaç, Numerical investigation of convective heat transfer in unsteady flow past two cylinders in tandem arrangements. Int. J. Heat Fluid Flow 29, 1309-1318 (2008)

12. H. S. Yoon, J. B. Lee, J. H. Seo, H. S. Park, Characteristics for flow and heat transfer around a circular cylinder near a moving wall in wide range of low Reynolds number. Int. J. Heat and Mass Transfer 53, 5111-5120 (2010)

13. A. Quintino, Experimental analysis of the heat transfer coefficient enhancement for a heated cylinder in cross-flow downstream of a grid flow perturbation. App. Thermal Eng. 35, 55-59 (2012)

14. C. Sak, R. Liu, D. S. K. Ting, G.W. Rankin, The role of turbulence length scale and turbulence intensity on forced convection from a heated horizontal circular cylinder. Exper. Thermanl and Fluid Science 31, 279-289 (2007)

15. E. Buyruk, H. Barrow, I. Owen, The influence of adjacent tubes on Convection Heat Transfer from a Heated Tube in Cross-flow. Fourth UK National Conference on Heat Transfer, I. Mech. E. Conference Trans., 135-139 (1995)

16. S. Sanitjai, R. J. Goldstein, Forced convection heat transfer from a circular cylinder in crossflow to air and liquids. Int. J. Heat and Mass Transfer 47, 4795-4805 (2004)

17. J. W. Scholten, D. B. Murray, Unsteady heat transfer and velocity of a cylinder in cross flow I1. High freestream turbulence. Int. J. Heat Mass Transfer 41, 1149-1156 (1998)

18. R. Lenhard, K. Kaduchová, J. Jandačka, J., Numerical Simulation in Indirectly heated hot Water Heater. Adv. Material Research, 1693-1697 (2014)

19. A. Bejan, A. D. Kraus, Heat transfer Handbook. John Wiley and sons, Inc., Hoboken, New Jersey, (2003)

20. V. P. Isatchenko, V. A. Osepova, A.S. Sukomel, Heat transfer (Теплопередача). Energoizdat, Moskva (1981)

21. А. Zhukauskas, A. Slantchiauskas, Heat transfer at trubulent fluid flow (Tеплоотдача в турбулентном потоке жидкости). Mintis, Vijnius, Litva (1973)

22. H. Hausen, Heat transfer in co-current, conter-current and cross flow (Wärmeübertragung im Gegenstrom, Gleichstrom und Kreuzstrom). Springer Verlag, Berlin, Heidelberg, (1976)

23. M. Kaviany, Principle of Convective Heat Transfer. Springer-verlag, New York, Inc. Second edition, ISBN 0-387-95162-8, (2001)

24. S. O. Atayilmay, Transient and steady-state natural convection heat transfer from a heated horizontal concrete cylinder. Int. J. of Thermal Sci. 49, 1933-1943 (2010) 